\title{
METODOLOGIA E PESQUISA NA PÓS-GRADUAÇÃO: a experiência do Mestrado Profissional em Políticas Públicas, Gestão e Avaliação da Educação Superior - MPPGAV/UFPB
}

\section{LUIZ DE SOUSA JUNIOR}

Doutor em Educação pela Universidade de São Paulo (USP). Vinculado ao MPPGAV da Universidade Federal da Paraíba (UFPB). Participa do Grupo de Pesquisa: Observatório da Remuneração Docente - PORD do CNPq. E-mail: luizsjunior@gmail.com

\section{MARIA DA SALETE BARBOZA DE FARIAS}

Doutora em Sociologia pela Universidade Federal de Pernambuco (UFPE); professora do MPPGAV da Universidade Federal da Paraíba (UFPB); Ex-coordenadora do MPPGAV/UFPB.email: runasvida@gmail.com 
RESUMO: Este artigo objetiva contribuir para o debate sobre a questão metodológica e da pesquisa no campo dos Mestrados Profissionais em Educação. Nele, procura-se explicitar as bases epistemológicas que vem guiando os procedimentos técnico-operacionais na gestação dos trabalhos finais, bem como os dilemas e desafios dessa modalidade de pós-graduação.

Palavras-chaves: Metodologia. Pesquisa. Mestrados Profissionais.

RESUMEN: Este artículo tiene como objetivo contribuir al debate sobre la cuestión metodología y la investigación en el campo Master Profesional en Educacion. En él, se trata de explicar las bases epistemológicas que ha guiado los procedimientos técnico-operativos en la gestación de la obra final, así como los dilemas y desafíos de este modelo de pos graduación.

Palabras claves: Metodología. Pesquisa. Master Profesionales en Educacion.

\section{METODOLOGIA E PESQUISA NA PÓS-GRADUAÇÃO: a experiência do Mestrado Profissional em Políticas Públicas, Gestão e Avaliação da Educação Superior - MPPGAV/UFPB}

\section{Introdução}

A expansão dos cursos de Mestrados Profissionais (MP) no Brasil tem sido uma constante nos últimos dez anos. Embora previsões legais tenham sido estabelecidas desde a década de 1960, o fato é que essa nova configuração de Pós-graduação stricto sensu veio a se espraiar decisivamente a partir dos anos de 1990. Atualmente, existem 1.056 cursos de MP em funcionamento ${ }^{1}$ sendo mais de 40 na área de Educação.

Conforme está expresso na Portaria da Coordenação de Aperfeiçoamento de Pessoal de Nível Superior - CAPES 080/1998, que trata do reconhecimento dos mestrados profissionais, sua criação decorre, em primeiro lugar, da necessidade da formação de profissionais pós-graduados que estejam habilitados a conceber novas técnicas e processos, com desempenho diferenciado de egressos dos cursos de mestrado que visem, preferencialmente, a um aprofundamento de conhecimentos ou técnicas de pesquisa científica, tecnológica ou artística.

1 Informação disponível em https://sucupira.capes.gov.br/sucupira/public/consultas/coleta/programa/listaPrograma.jsf 
Como todo processo inovativo na formação em nível de Pós-graduação, a consolidação dos MP se dará no momento em que suas bases metodológicas e de pesquisa estiverem sedimentadas o suficiente para se constituir um campo de definições de uma práxis acadêmica, vale dizer, de uma orientação técnico-científica que incorpore dimensões de produção de novos saberes e aplicabilidade do conhecimento em construção.

Este artigo pretende, de forma breve, expor alguns elementos que contribuam para a discussão metodológica e da pesquisa no campo de MP, especificamente, em Mestrado Profissional em Educação (MPE), com base nos primeiros resultados apontados nos trabalhos de dissertação apresentados no Mestrado Profissional em Políticas Públicas, Gestão e Avaliação - MPPGAV da Universidade Federal da Paraíba (UFPB). Nele, procura-se explicitar as bases epistemológicas que vem guiando os procedimentos técnico-operacionais na gestação dos trabalhos de conclusão do curso, bem como os dilemas e desafios dessa modalidade de Pós-graduação.

\section{Metodologia e Pesquisa na Pós-graduação}

Importante refletir, inicialmente, sobre o conceito de pesquisa e sobre o sentido da pertinência e aplicabilidade da pesquisa na pós-graduação e particularmente nos MP. Iniciando, recorre-se a sugestiva colocação de Bernadette Gatti (2002), quando afirma que a pesquisa é, primeiramente, "obter conhecimentos sobre alguma coisa". Destarte, pesquisa requer dúvidas, busca de outros saberes. Saber é poder e o homem sabe quando interroga, observa a natureza para compreender e dispor sobre ela. Como bem lembra a autora,

Pesquisa é o ato pelo qual procuramos obter conhecimento sobre alguma coisa. [...] Contudo, num sentido mais estrito, visando a criação de um corpo de conhecimentos sobre um certo assunto, o ato de pesquisar deve apresentar certas características específicas. Não buscamos, com ele, qualquer conhecimento, mas um conhecimento que ultrapasse nosso entendimento imediato na explicação ou na compreensão da realidade que observamos (GATTI, 2002, pp. 9-10).

Ao possibilitar a construção de novos conhecimentos, ela em si é germinadora de aprendizagens tanto para o pesquisador quanto para a comunidade onde se encontra inserido. 
Sabe-se que os níveis de pesquisa variam de acordo de acordo com os objetivos que a própria pesquisa se propõe: exploratória, descritiva, explicativa. Temos, também, "delineamentos" de pesquisa que vão desde a pesquisa bibliográfica, documental, experimental, estudo de caso, estudo de campo enfim tipos diferentes de pesquisa que perpassam a pesquisa de mercado, pesquisa científica, pesquisa de opinião, advindo leque de possibilidades para compreendermos o seu verdadeiro conceito. O conhecimento científico não é gerado espontaneamente, mas produzido a partir de uma realidade social e econômica, cuja interpretação depende de valores humanos e sociais. Daí a necessidade de problematizá-lo para que não se tenha a neutralidade por atributo.

A ciência é um ato político, repleto de racionalidades. Exige tempo, condições materiais e espirituais, que vão desde o financiamento à disponibilidade, compromisso, ética e, sobretudo, que tenha reverberação positiva ao todo social, e particularmente à classe trabalhadora. $O$ ponto de partida da pesquisa, seu objetivo imediato é a aquisição de conhecimento, mas no sentido amplo ela deve assegurar/visar o desenvolvimento do ser humano. Ferreira (2009, p.01) define a "pesquisa como uma ação intencional e metodologicamente estruturada na busca de uma resposta para uma pergunta previamente elaborada".

Dito isto, é possível lembrar que a pesquisa no Brasil teve, praticamente, o seu início nos anos de $1930,{ }^{2}$ quase que imbricada com a história das Universidades, mediante tentativas de implantar instituições universitárias centradas em torno de institutos científicos e culturais avançados. Os primeiros momentos apontavam para um modelo de pesquisa tendo por base epistemológica o positivismo e a utilização predominante do método quantitativo. Este método passa a ser questionado nos anos 1960, ganhando relevo dentre outras metodologias, o método qualitativo, e com ele as duas grandes abordagens: fenomenologia e a dialética. Com o primeiro alinhavam-se as abordagens antropológicas, estudos etnográficos, estudos de caso, a pesquisaação, a pesquisa participante, histórias de vida, etc. Com o segundo, o método dialético e suas categorias metodológicas, para tentar dar conta do real - da totalidade do processo, sempre reforçando a necessária pertinência e validade da pesquisa chancelada pelo diálogo e pela dinâmica interlocução sujeito/objeto e seu contexto, rigor e ética.

Igualmente, é bom lembrar que a institucionalização da Pós-graduação não somente trouxe a pesquisa para dentro da Universidade, mas propiciou o intercâmbio institucional e acadêmico desde a criação do INEP em 1938 até as Associações de pesquisas, provocando nova dinâmica e desdobramentos para pesquisa e para a realidade educacional do país. No campo das Ciências

2 Em 1916 foi criada a Sociedade Brasileira de Ciências, considerada uma das primeiras manifestações organizacionais da época, passando em 1922 para Academia Brasileira de Ciências. Na Educação, em 1924, foi criada a Associação Brasileira de Educação (FERNANDES, 2000, p.28.),seguida na década de 1938, a criação do INEP. 
Humanas e da Educação destaca-se, nos anos de 1970, o nascimento da Associação de PósGraduação em Ciências Sociais - ANPOCS e, mais adiante, da Associação Nacional de Pesquisa em Educação - ANPED, associações nacionais acadêmicas com bastante representatividade, que irão problematizar e trabalhar as suas questões de pesquisas em âmbito próprio.

Assim, a educação nacional e, particularmente, a Pós-graduação, com suas perspectivas, seus problemas, torna-se objeto de estudo de diferentes áreas, bem como se tornaram fulcros de iniciativas tomadas por setores sociais os mais diversificados do ponto de vista profissional político e cultural conduzindo a consensos balizadores da problemática educacional.

A Pós-graduação e suas instituições afins em muito influenciaram na formulação de políticas que se efetivaram e se renovaram ao longo dos anos, bem como na elaboração de mecanismos de acompanhamento e avaliação da produção realizada/desenvolvida nos vários programas, a exemplo do que foi sendo consolidado pela CAPES. Pesquisa e pós-graduação a nosso ver estão profundamente imbricadas, o que nos permite dizer que a consolidação da pesquisa precedeu a existência de uma pós-graduação consistente e de qualidade.

Neste sentido, a pertinência e aplicabilidade da pesquisa nos MPE são fundamentais. Em nosso entendimento, a responsabilidade da pesquisa se faz em torno de temas que tenham desdobramentos reflexivos e práticos no cotidiano educacional e institucional, trazendo riqueza teórica e prática reflexiva, sinalizando pistas metodológicas criativas para desvendar novos horizontes investigativos, com achados que possam incidir na própria prática profissional. É fato que, em termos de MPE, o Brasil apenas engatinha na construção dessa nova arquitetura da formação de profissionais em nível de Pós-graduação stricto sensu. Existe, portanto, um vasto campo de conhecimento a ser desbravado seja do ponto de vista metodológico, seja do ponto de vista da pesquisa em geral.

Há que se estabelecer, ainda, a complexidade do tema frente ao pouco acúmulo de estudos pertinentes aos MP, com suas estratégias e peculiaridades. Nesse sentido, Fischer (2005, p. 27), atenta para o fato de que os MP vêm se estruturando em dois modelos: o curso generalista e o curso focalizado. Para a autora, o Mestrado Profissional generalista é próprio da área de Administração; já o Mestrado Profissional focalizado diz mais respeito à áreas de viés tecnológico e de políticas públicas, ou seja, em áreas de aplicação setorializada. Essa categorização, embora bastante restrita, contribui para elucidação de alguns aspectos da questão metodológica no âmbito dos MP.

De fato, o que aparenta ser um modelo de cunho generalista, desenvolve-se mais como uma estrutura que cultiva, por necessidade e não por diletantismo, uma postura interdisciplinar, 
com interlocução entre várias áreas do conhecimento e suas respectivas disciplinas. Tal situação, em se configurando um elemento forte na construção epistemológica, necessita, por outro lado, de bases teóricas e conceituais bem estabelecidas de modo que a interdisciplinaridade não se configure em uma mera justaposição de disciplinas, mas em um encontro profícuo e enriquecedor de possibilidades de experiências diversas e únicas, evitando-se, desse modo, a postura reducionista de generalidades superficiais.

Trata-se, na visão de Boaventura Sousa Santos (2004), de um movimento que ocorre no ensino superior que é o da passagem do conhecimento universitário para o conhecimento pluriversitário. Partindo do ponto de vista de que se estabeleceu uma crise institucional que, segundo o autor, levou à descapitalização das universidades, descaracterização intelectual, crise de legitimidade e crescente desvalorização dos diplomas universitários. Santos, advoga que na medida em que o Estado passou a compreender o ensino superior e a educação em geral como um bem público, mas sem o necessário e exclusivo financiamento, a crise se abateu sobre essas instituições. $\mathrm{O}$ autor enfatiza que essa crise brota de uma nova hegemonia resultante do processo de fortalecimento do pensamento neoliberal em nível mundial. Tal advento veio a exacerbar a mercantilização do ensino, inicialmente restrita ao campo nacional, em pequena escala, evoluindo na contemporaneidade para um mercado transnacional de educação superior.

Desse modo, a descapitalização das instituições universitárias públicas e a transnacionalização do ensino superior resultaram num movimento de perda da autonomia universitária, do poder de decisão dos pesquisadores sobre seus estudos e, por consequência, a chamada liberdade de cátedra, tal como era concebida, perdeu sua razão de ser frente à necessidade de aplicabilidade quase que imediata dos produtos resultantes das pesquisas desenvolvidas no âmbito das instituições universitárias. Segue-se outro momento, agora relativo ao conhecimento pluriversitário, tendo como eixo central de organização a aplicação que lhe pode ser dada. Santos (2004) ressalta que como essa necessidade de utilização se dá extramuros, forja-se, necessariamente, uma partilha entre pesquisadores e utilizadores. $\mathrm{O}$ ethos universitário assentado no paradigma disciplinar perde sua condição de estabilidade. A ele, sucede o ethos da produção do conhecimento mercantil e profunda integração entre universidade e empresa (indústria).

A este movimento, responde Boaventura Sousa Santos com uma necessária interlocução das universidades com amplos setores da sociedade, tendo como princípio de intervenção a pesquisa-ação, que consistiria na "definição e execução participativa de projectos de pesquisa, envolvendo as comunidades e organizações sociais populares a braços com problemas cuja solução pode beneficiar dos resultados da pesquisa" (SANTOS, op. cit. p. 75). 
Tal interlocução deve-se somar ao que o sociólogo português define como ecologia dos saberes (Santos, 2004), que seria um aprofundamento da pesquisa-ação. Tal postura implicaria em reconhecer os "saberes leigos", isto é, saberes populares, urbanos, camponeses etc.

Essa reinvenção da pesquisa encontra, evidentemente, obstáculos no que se refere à sua validação, considerando os critérios clássicos como validade, fidedignidade e generalização que as agências de fomento à pesquisa usualmente utilizam em suas avaliações. Surge, pois, a necessidade de encontrar novos modelos ou paradigmas de validação científica, a exemplo de plausibilidade, credibilidade e transferência, dentre muitos outros (ANDRÉ, 2001, p. 58), sem, contudo, resultar em perda da qualidade acadêmica. Esses desafios estão presentes para os cursos de pós-graduação acadêmicos. Porém, eles se tornam mais difíceis de serem enfrentados nos Mestrados Profissionais, sobretudo em virtude dessa aproximação com o mercado, com setores da administração pública e da sociedade civil.

\section{O Mestrado Profissional em Educação da UFPB: alargando possibilidades}

Diferentemente de outros cursos de Mestrado Profissional em Educação, os quais, em geral, têm foco na resolução de problemas da área do ensino e da docência, a proposta de criação do Mestrado Profissional em Políticas Públicas, Gestão e Avaliação - MPPGAV procurou atender, inicialmente, a demanda de Servidores Técnico-Administrativos (STAs) de nível superior da Universidade Federal da Paraíba - UFPB ${ }^{3}$ no contexto de forte expansão das universidades federais por conta do Decreto $\mathrm{n}^{\mathrm{0}}$ 6.096, de 24 de abril de 2007, que criou o Programa de Apoio a Planos de Reestruturação e Expansão das Universidades Federais (Reuni). Com efeito, em decorrência desse Programa, as Universidades Federais se viram compelidas a expandir cursos de graduação e melhorar a qualidade da oferta desses cursos com eficientização dos recursos humanos. Embora não possa estar isento de críticas, sobretudo quanto aos seus objetivos, metas e aporte de recursos, o Reuni trouxe necessidade de melhoria do trabalho executado no âmbito das atividades-meio das instituições federais.

3 A proposta inicial foi estendida as Instituições Federais de Ensino Superior do Estado Paraíba, abrangendo a Universidade Federal da Campina Grande (UFCG) e o Instituto Federal de Educação, Ciência e Tecnologia da Paraíba - IFPB. Atualmente o Curso é destinado aos STAs das IES públicas do país. 
Em se tratando, especificamente, dos recursos humanos e gestão de pessoas, a expansão quantitativa da UFPB foi acompanhada de outras mudanças que atingiram a estrutura dos cargos de docentes e STAs, a exemplo da abertura de novos concursos, decorrente não apenas de vagas geradas pelo Reuni, mas também da criação do banco de professor-equivalente e do quadro de referência dos servidores técnico-administrativos, que permitiu a reposição de vagas quando de aposentadoria do (a) servidor (a), além de importantes alterações nos Planos de Cargos, Carreira e Remuneração tanto de docentes quanto dos STAs. Em relação a este último segmento da comunidade universitária, o Plano de Carreira dos Cargos Técnico-Administrativos em Educação (PCCTAE), por meio da Lei $\mathrm{n}^{\circ}$ 11.091, de 12 de janeiro de 2005 trouxe inquestionáveis avanços no que se refere à capacitação e aperfeiçoamento dos servidores. O Decreto $\mathrm{N}^{\mathrm{o}} 5.824$, de 29 de junho de 2006, por sua vez, estabeleceu os procedimentos para a concessão do Incentivo à Qualificação e para a efetivação do enquadramento por nível de capacitação dos servidores integrantes do Plano de Carreira dos Cargos Técnico-Administrativos em Educação, instituído pela Lei no $11.091 / 2005 .^{4}$

Em razão desses fatores (expansão das IFES, mudanças nos Planos de Carreira e reposição de pessoal), aconteceu um previsível e desejado movimento de renovação do quadro de pessoal da instituição. Em se tratando dos servidores técnico-administrativos, no ano de 2010, a UFPB contava com 3.668 servidores, sendo que desse montante, 1.145 STAs possuíam formação de nível superior, ou seja, um expressivo contingente de mais de $30 \%$.

Nesse ínterim, a administração superior da instituição criou uma comissão de alto nível com o objetivo precípuo de avaliar e redimensionar o quadro de servidores técnico-administrativos da UFPB. Esse estudo iria subsidiar a política de capacitação e aperfeiçoamento dos STAs. E, de fato, a comissão concluiu pela necessidade de melhoria do desempenho funcional dos servidores e adequação da capacidade e competências desse segmento ao ambiente de trabalho em face da nova etapa de crescimento institucional.

Emergiu desse novo momento histórico a possibilidade concreta de implantação de um curso de Pós-graduação stricto senso destinados aos servidores da UFPB, cuja finalidade seria a de preencher um vazio na formação do quadro de servidores da instituição em face aos novos desafios que o mundo globalizado cobra das Instituições de Ensino Superior (IES), considerando a complexidade da sociedade contemporânea e suas idiossincrasias.

4 A legislação sobre o PCCTAE foi consultada a partir de material compilado e publicizado pela FASUBRA (2013). 
Nesse contexto, a UFPB buscou inserir no âmbito da política de capacitação dos seus servidores técnico-administrativos a possibilidade de implantar um curso de Mestrado Profissional, a exemplo de outras universidades públicas, naquele momento, como a Universidade Federal do Ceará (UFC), na Universidade Federal de Santa Catarina (UFSC) e Universidade de Brasília (UnB).

A proposta procurou se adequar às diretrizes da Portaria Normativa $\mathrm{N}^{\mathrm{o}} 17$ de 28/12/2009, vislumbrando um possível diálogo acadêmico-profissional concernente a associação entre o ensino de pós-graduação e a atividade profissional, conforme dispõe $\mathrm{o}$ artigo $2^{\circ}$ da portaria anteriormente citada. Nesse sentido, o MPPGAV nasce com uma identidade própria, na medida em que busca o aprimoramento da capacitação profissional dos STAs, de natureza distinta daquela que, usualmente, é propiciada pelo Mestrado Acadêmico.

Como primeiro "estágio" da constituição do MPPGAV, foi ofertado, em 2011, o Curso de Especialização em Gestão e Avaliação da Educação Superior destinado exclusivamente aos servidores da UFPB. Essa experiência pioneira contribuiu para popularização da ideia e, sobretudo, para o aprimoramento da proposta do Mestrado Profissional, considerando o diálogo estabelecido tanto na relação entre docentes quanto, docentes e STAs e mesmo estre os próprios servidores participantes da Especialização. Assim, com base nessa construção coletiva e assentada em uma compreensão de "unidade na diversidade" foram se constituindo os campos de investigação a serem objetos de estudo e pesquisas do futuro MP. Em decorrências desse processo rico de interação entre pesquisadores e STAs, foram se consolidando duas linhas de pesquisa, a saber: a) Políticas Públicas de Gestão e Avaliação; e b) Gestão, Avaliação e Financiamento do Ensino Superior ${ }^{5}$.

A Linha de Políticas Públicas de Gestão e Avaliação tem projetos de estudos direcionados para gestão e avaliação das políticas públicas, na esfera federal, estadual e municipal. Preocupa-se, ainda, com avaliação e impacto na formulação das políticas públicas voltadas para as instituições federais de ensino superior e, por fim, pretende analisar e propor novas metodologias para gestão e avaliação de políticas públicas

Jáa segunda linha, Gestão, Avaliação e Financiamento do Ensino Superior, busca desenvolver projetos com ênfase no desenvolvimento científico e tecnológico e com foco privilegiado para as políticas de financiamento nacionais e internacionais para a educação superior. Esta linha

5 De acordo com a Resolução do CONSEPE/UFPB, $n^{\circ}$ 19/2015 as linhas de pesquisa ficaram assim denominadas: Linha 1 - Políticas Públicas de Gestão da Educação Superior; Linha 2 - Avaliação e Financiamento da Educação Superior. 
tem por objetivo, também, analisar e propor estratégias para superar os desafios impostos pela flexibilização da gestão, modalidades de financiamento de sistemas organizacionais de gestão da educação e avaliação institucional.

As duas linhas de pesquisa foram a base da constituição da área de concentração denominada de Politicas Públicas, Gestão e Avaliação, tendo como campo de estudo as IES em virtude de sua importância para o desenvolvimento científico e tecnológico do Brasil, da região Nordeste do Brasil e, particularmente, para o estado da Paraíba, sede do curso. O MPPGAV teve selecionada a sua primeira turma para o inicio do ano de 2015.

\section{Desafios da teoria e prática: o Trabalho Final}

De acordo com o princípio de que a pesquisa é fundamental para que os Mestrados Profissionais em Educação possam contribuir de forma investigativa e crítica para melhoria da prática profissional dos profissionais dessa Área, o MPPGAV, traz em seu novo regulamento, Resolução do CONSEPE/UFPB 19/2015, “[...] desenvolver atividades de ensino, pesquisa e extensão que visem à consolidação e à ampliação das linhas de pesquisa [...]", bem como o fortalecimento das “[...] atividades de ensino, pesquisa e extensão de forma sistemática, através da institucionalização de linhas de pesquisa, permanentemente alimentadas por novos projetos, novos pesquisadores e pessoal qualificado" (p. 3). A estrutura curricular prevê a duração do curso de, no mínimo, 12 (doze) meses e, no máximo, 24 (vinte e quatro) meses, distribuídos em 02 (dois) períodos letivos regulares por ano civil. Os mestrandos deverão cursar o cursar 14 (quatorze) créditos em disciplinas obrigatórias, vinculadas a área de concentração do Curso e 10 em disciplinas optativas vinculadas as respectivas linhas de pesquisa.

Ainda de acordo com o Regulamento, o artigo 31, estabelece que o Trabalho Final, requisito para obtenção do grau de Mestre, deverá oferecer contribuição para a gestão e avaliação de políticas públicas e poderá ser apresentado na forma de "Dissertação", "Artigo" ou "Estudo de Caso", devendo o projeto de pesquisa estar relacionado com a temática das políticas públicas, da gestão e de sua avaliação, e que apresente como características principais: plausibilidade e viabilidade.

O foco do MPPGAV é a formação de pessoal qualificado técnica e cientificamente dos servidores técnicos e administrativos do quadro permanente das instituições de ensino superior, 
para o exercício de suas atividades profissionais, na gestão e avaliação de políticas públicas. As temáticas investigadas, de acordo com a proposta dos Mestrados Profissionais e particularmente do MPPGAV deverão problematizar questões relacionadas a sua prática profissional cotidiana direta ou de forma indireta às questões ligadas ao campo institucional mais amplo, que são as instituições de ensino superior - lócus de atuação dos mestrandos. Neste aspecto, concordamos com Hetkowiski (2016), ao reafirmar que os trabalhos finais de conclusão, devem se voltar para a atividade profissional dos mestrandos, reforçando assim o sentido da aplicabilidade da pesquisa.

É imperativo que a elaboração do Trabalho de Conclusão Final de Curso - TCFC seja precedida da pesquisa no sentido de vivamente contribuir para que o mestrando tenha oportunidade de analisar, problematizar a realidade em que está inserido, por meio de opções teóricos-metodológicas refletidas e sistematizadas, numa substantiva articulação teoria e prática. É importante informar que o MPPGAV foi submetido ao APCN - Aplicativo de Propostas de Cursos Novos da Capes, em 2012. Passou por diligência em 2014 e teve a recomendação do Conselho Técnico Científico (CTC) da CAPES em 2014. O funcionamento oficial do Curso teve inicio em 13 de março de 2015, de modo que, obedecendo ao prazo regulamentar, a primeira turma defendeu seus trabalhos de conclusão de curso em fevereiro de 2016. Foram matriculados 40 mestrandos (30 da UFPB, 05 da UFCG e 05 do IFPB); ocorrendo duas desistências ainda no início das atividades acadêmicas, sendo uma por motivo de saúde e outra por opção a outro Programa. Ao longo dos dois anos, cursaram e concluíram (defenderam a dissertação) 38 mestrandos. Os TCFC, em sua maioria, se inseriram na modalidade "dissertação" e "estudo de caso". Em virtude da exiguidade do tempo, não nos foi permitido fazer um detalhamento analítico da produção da primeira turma ${ }^{6}$, principalmente, em termos de procedimentos de coleta de dados e análise. Entretanto, podemos exemplificar algumas temáticas trabalhadas, a saber: retenção e evasão no curso de Engenharia de Alimentos da UFPB; impacto da bolsa estágio na formação de estudantes de pedagogia; análise da aplicação de recursos do PROAP/UFPB; o papel da UFPB no sistema de inovação tecnológico do estado da Paraíba; expansão e democratização da Educação Superior na UFPB; impactos do Reuni no curso de Serviço Social da UFPB; marco regulatório da pósgraduação stricto senso na UFPB: balizas jurídicas ao desenvolvimento institucional e análise comparativa da eficiência das compras de hortifrúti da UFPB.

Como se pode perceber são temáticas voltadas para ampliar e contribuir a presença da Universidade no contexto de desenvolvimento regional e, também, de avaliar e propor melhorias para o desenvolvimento das atividades meio e fim da instituição universitária.

6 Pretende-se elaborar ainda no ano de 2017 um relatório conclusivo acerca dos trabalhos de dissertação produzidos pela primeira turma do MPPGAV, bem como realizar o acompanhamento dos egressos. 


\section{Considerações finais}

Este artigo procurou esboçar uma breve análise acerca do debate sobre a questão metodológica e da pesquisa acerca dos Mestrados Profissionais em Educação, considerando os desafios impostos num momento em que prepondera uma visão mercantilista e reducionista do fazer acadêmico.

De fato, é esta postura que constitui um dos principais entraves para a produção do conhecimento. Submetido a prazos rigorosos, encontra-se, hoje, dificuldades para o processo de amadurecimento do pesquisador e de seu estudo. A ênfase para se buscar soluções imediatistas, que atendam às exigências do mercado, impõe um novo ritmo de produção acadêmica. Mas, por outro lado, acreditamos haver "brechas", não somente para a produção de trabalhos de qualidade no âmbito dos MPE; mas, também, para a busca de melhoria das práticas profissionais e da utilização eficiente e democrática dos recursos públicos. Nesse sentido, julgamos necessário dar ênfase à discussão de ordem ética acerca do papel do pesquisador-trabalhador e sua inserção no cotidiano de seu local de trabalho.

Por fim, Consideramos de fundamental importância o desenvolvimento de pesquisas para acompanhar o percurso dos mestrandos de MPE e avaliar a contribuição do Programa para a dinâmica profissional pós-conclusão do curso. Importante ainda é verificar como os trabalhos produzidos, com seus respectivos produtos, são recebidos pela instituição originária e que mudanças estão a operar nessas instituições.

\section{REFERÊNCIAS}

ANDRÉ, Marli. Pesquisa em educação: buscando rigor e qualidade. Cadernos de Pesquisa, n. 113, jul. 2001, pp. 51-64. Disponível em http://dx.doi.org/10.1590/S0100-15742001000200003 Acesso em março de 2017.

ANDRÉ, M. Ensinar a pesquisar: como e para quê? In: VEIGA, I. P. A. (Org.). Lições de Didática. Campinas: Papirus, 2012. p. 123-134.

BRASIL. Portaria $\mathbf{N}^{0}$ 80, de 16 de dezembro de 1998. Dispõe sobre o reconhecimento dos 
mestrados profissionais e dá outras providências. Disponível em: https://www.capes.gov.br/ images/stories/download/avaliacao/avaliacao-n/1892015-Portaria-CAPES-080-1998.pdf Acesso em 22/02/2017.

FEDERAÇÃO DE SINDICATOS DAS UNIVERSIDADES BRASILEIRAS. Plano de Carreira: rumo à carreira (Lei No 11.091 Publicada em Janeiro de 2005 - Atualizada). FASUBRA, maio de 2013.

FERREIRA, L.S. A pesquisa educacional no Brasil: tendências e perspectivas. Contrapontos. Volume 9 n $^{\circ} 1$ - pp. 43-54 - Itajaí, jan/abr 2009.

FERNANDES, Ana Maria. A construção da Ciência no Brasil e a SBPC. $2^{\text {a }}$. Ed. Brasília: Editora UNB. 2000.

FISCHER, Tânia. Mestrado profissional como prática acadêmica. R B P G, v. 2, n. 4, p. 24-29, jul. 2005.

GATTI, B. A. A construção da pesquisa em educação no Brasil. Brasília: Plano Editora, 2002.

HETKOWISKI, T. M. Mestrados Profissionais em Educação: políticas de implantação e desafios às perspectivas metodológicas. Revista Plurais. Salvador, v. 1, n. 1, p. 10-29, jan./abr. 2016.

SANTOS, Boaventura Souza, A universidade do século XXI: para uma reforma democrática e emancipatória da universidade. São Paulo: Cortez, 2004. (Coleção questões da nossa época, v. 120)

UNIVERSIDADE FEDERAL DA PARAÍBA. CONSELHO SUPERIOR DE ENSINO, PESQUISA E EXTENSÃO. Resolução 19/2015. Revoga a Resolução no 13/2012 do Consepe, aprova e dá nova redação ao Regulamento e à estrutura Acadêmica do Mestrado Profissional em Políticas Públicas, Gestão e Avaliação - MPPGAV, em nível de Mestrado Profissional, sob a responsabilidade do Centro de Educação. João Pessoa, 16 de junho de 2015. 